https://doi.org/10.15407/dopovidi2021.06.131

УДК 628.161:546.19-3](045)

А.І. Бондарєва, https://orcid.org/0000-0003-3064-1725

Ю.М. Холодько, https://orcid.org/0000-0002-2514-767X

В.Ю. Тобілко, https://orcid.org/0000-0002-1800-948X

Б.Ю. Корнілович, https://orcid.org/0000-0002-6393-6880

Національний технічний університет України

"Київський політехнічний інститут ім. Ігоря Сікорського"

E-mail: a.i.bondarieva@gmail.com

\title{
Видалення сполук арсену з природних і стічних вод із використанням нанорозмірного заліза
}

Представлено членом кореспондентом НАН України Б.Ю. Корніловичем

Досліджено фізико-хімічні особливості видалення сполук арсену з природних і стічних вод із використанням нанорозмірного заліза, нанесеного на поверхню глинистих мінералів. Встановлено, що одержані матеріали мають значно кращі сорбційні властивості щодо вилучення арсену з водних розчинів порівняно з природними силікатами. Проаналізовано процеси кінетики сорбції арсенат-іонів зразками стабілізованого нанорозмірного заліза за допомогою кінетичних моделей адсорбиій псевдопершого та псевдодругого порядків. Встановлено, що кінетична залежність сорбиії $A s(V)$ одержаними матеріалами краще описується моделлю псевдодругого порядку. Показано, що сорбенти на основі нанорозмірного заліза ефективно вилучають токсичні іони арсену із забруднених вод.

Ключові слова: арсен, очищення вод, адсорбція, нанорозмірне залізо, силікатні сорбенти.

Одними з найбільш небезпечних забруднювачів поверхневих, підземних і стічних вод є сполуки арсену (As), які характеризуються значною токсичною дією на всі живі організми [1]. Тривалий вплив As на людський організм призводить до його полісистемних дисфункцій. Сполуки арсену спричиняють захворювання шкіри (меланоз, кератоз, гіперпігментацію), впливають на дихальну (порушення функцій легень, бронхіт), нервову (невропатія, енцефалопатія) та серцево-судинну системи, збільшують ризик виникнення ракових захворювань [2, 3]. Саме тому Всесвітньою організацією охорони здоров’я (ВОО3) рекомендовано концентрацію As у питній воді на рівні, що не перевищує 10 мкг/дм³.

Для сполук арсену характерним є його існування в чотирьох ступенях окиснення $(-3$, $0,+3,-5)$, що залежить від концентрації розчиненого кисню, окисно-відновного потен-

Ци т у в ан н я: Бондарєва А.І., Холодько Ю.М., Тобілко В.Ю., Корнілович Б.Ю. Видалення сполук арсену з природних і стічних вод із використанням нанорозмірного заліза. Допов. Наи. акад. наук Укр. 2021. № 6. C.131-138. https://doi.org/10.15407/dopovidi2021.06.131 
ціалу та рН водного середовища. Найбільш поширені неорганічні форми As, які у водних об’єктах із анаеробними умовами зустрічаються у вигляді арсенітних $\left(\mathrm{H}_{3} \mathrm{AsO}_{3}^{0} \mathrm{Ta}_{2} \mathrm{AsO}_{3}{ }^{-}\right)$, а в окиснювальних умовах - арсенатних форм $\left(\mathrm{H}_{2} \mathrm{AsO}_{4}^{-}\right.$та $\left.\mathrm{HAsO}_{4}^{2-}\right)[4,5]$.

Забруднення арсеном грунтових вод відбувається переважно за рахунок природних процесів вивітрювання та вилуговування з арсенвмісних порід [6]. У поверхневі водойми він потрапляє разом зі стічними водами підприємств кольорової металургії, лакофарбних та поліграфічних виробництв, внаслідок сільськогосподарської діяльності та ін. [5].

Проблема вмісту As у поверхневих та грунтових водах визнана в багатьох країнах світу і не залежить від рівня їх економічного розвитку (США, Угорщина, Китай, Мексика, Індія тощо). В окремих регіонах його концентрація в природних водоймах досягає десятків і сотень мікрограмів у 1 дм $[3,7]$.

Під час вибору методу видалення іонів арсену з водних об’єктів необхідно враховувати ix хімічний склад, pH середовища, ступінь окиснення As i економічну доцільність технологічних рішень. Сучасні способи очищення природних і стічних вод від сполук арсену переважно базуються на коагуляції, іонному обміні, адсорбційних і мембранних процесах. Якщо арсен присутній у воді у формі арсенітів, то його, в більшості випадків, попередньо окиснюють до арсенатів за допомогою хімічних або електрохімічних методів [8, 9].

Високою ефективністю, особливо на етапах доочищення вод до рівня нижче ГДК, характеризуться сорбційні технології. Як сорбенти для видалення Аs використовують як природні та штучні неорганічні матеріали на основі активованого оксиду алюмінію, сполук лантану, гранульованих оксидів заліза, так і органічні - різноманітні кополімери, іонообмінні смоли з селективними функціональними групами тощо [8, 10].

Особлива увага приділяється матеріалам на основі нанорозмірного нульвалентного заліза $\left(\mathrm{Fe}^{0}\right)$ з високою реакційною здатністю до сполук $\mathrm{As}(\mathrm{III})$ та $\mathrm{As}(\mathrm{V})$ [8]. Стабілізація частинок $\mathrm{Fe}^{0}$ на органічних і неорганічних матрицях дає змогу уникнути їх агрегації та попереднього окиснення. Перспективними матеріалами для цього є природні глинисті мінерали та цеоліти [11].

Метою даної роботи було дослідження фізико-хімічних особливостей видалення сполук $\mathrm{As}(\mathrm{V})$ із природних і стічних вод з використанням стабілізованого нанорозмірного нульвалентного заліза.

Для одержання сорбційних матеріалів використовували очищені від домішок зразки природних глинистих мінералів - монтморилоніту (MМТ) та палигорськіту (ПГ). Після ультразвукової обробки суспензії алюмосилікату додавали розчин $\mathrm{FeCl}_{3} \cdot 6 \mathrm{H}_{2} \mathrm{O}$ певної концентрації і перемішували суміш протягом 1 год. Відновлення іонів $\mathrm{Fe}^{3+}$ здійснювали розчином борогідриду натрію $\mathrm{NaBH}_{4}$ в кислому середовищі. Масове співвідношення $\mathrm{Fe}^{0}$ до MMT (ПГ) становило 0,2 : 1. Після висушування під вакуумом за температури $60{ }^{\circ} \mathrm{C}$ отримані матеріали зберігали в герметичній тарі та інертній атмосфері [12].

Для контролю мономінеральності вихідних зразків глинистих мінералів і визначення фазового складу їх модифікованих форм використовували рентгенофазовий аналіз, який проводили за допомогою дифрактометра ДРОН-4-07 (діапазон 2-60² 2ө, відфільтроване випромінювання $\left.\mathrm{Cu} K_{\alpha}\right)$.

Вплив рН на процес сорбції вивчали за вихідної концентрації As(V) 5 мг/дм для зразків стабілізованого нанорозмірного заліза та 1 мг/дм³ для вихідних мінералів. В експе- 
Puc. 1. Залежність сорбції арсенат-іонів від рН водного середовища на зразках: 1 - MMT-Fe;

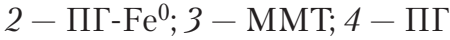

риментах з вивчення кінетики сорбції As(V) $з$ модельних розчинів на зразках ПГ- $\mathrm{Fe}^{0}$ і $\mathrm{MMT}-\mathrm{Fe}^{0}$ вихідна концентрація токсиканту становила 5 мг/дм ${ }^{3}$.

Дослідження процесів сорбції сполук As(V) стабілізованим нанорозмірним залізом вивчали в діапазоні вихідних концентрацій 0,1-13 мг/дм³ у статичних умовах за кімнатної температури та співвідношення твердої і рідкої фаз Т : $\mathrm{P}=1$ : 500.

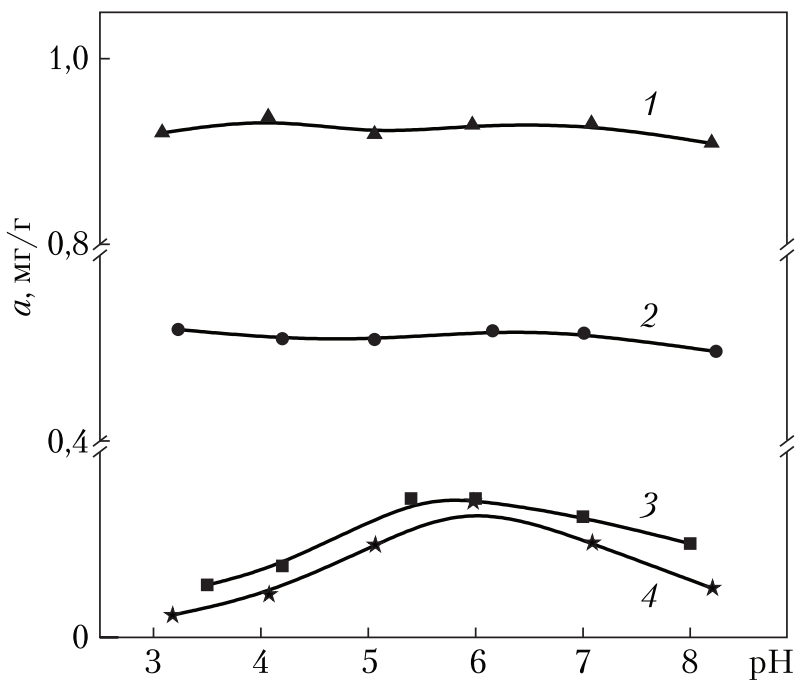
Для приготування модельних розчинів використовували стандартний розчин $\mathrm{H}_{3} \mathrm{AsO}_{4}$ з концентрацією 1000 мг/дм³ ${ }^{3}$ Іонну силу $(I=0,01)$ створювали 1 М розчином хлориду натрію. Значення величини рН корегували 0,1 М розчином $\mathrm{NaOH.} \mathrm{Після} \mathrm{встановлення} \mathrm{сорбційної} \mathrm{рівноваги} \mathrm{рідку} \mathrm{фазу} \mathrm{відділяли} \mathrm{цен-}$ трифугуванням і визначали в ній рівноважну концентрацію іонів As(V) методом атомноемісійної спектрометрії з індуктивно зв’язаною плазмою (Thermo Scientific iCAP 7400 ICPOES, США). Величину сорбції ( $a$, мг/г) арсенат-іонів розраховували за формулою

$$
a=\frac{\left(C_{\text {вих }}-C_{\text {рівн }}\right) V}{m},
$$

де $C_{\text {вих }}, C_{\text {рівн }}-$ вихідна та рівноважна концентрації металу, мг/дм ${ }^{3} ; V-$ об’єм розчину, дм ${ }^{3}$; $m$ - маса наважки сорбенту, г.

Дані рентгенофазового аналізу підтверджують мономінеральність природних глинистих мінералів та наявність модифікувального шару сполук заліза на їх поверхні. Так, на рентгенограмах зразків ПГ-Fе ${ }^{0}$ i MMT-Fe ${ }^{0}$ спостерігаються рефлекси, що відповідають кристалічній фазі $\alpha$-Fe, оксиду заліза $\mathrm{FeO}$ та оксигідроксидам заліза FeOOH [15].

Встановлено, що величина рН водного середовища впливає на процес сорбції арсенатіонів вихідними глинистими мінералами (рис. 1). Це обумовлено, як розподілом форм арсенатів у водному середовищі, так і хімією поверхні силікатів. Так, у кислому середовищі $\mathrm{As}(\mathrm{V})$ знаходиться в основному у формі $\mathrm{H}_{3} \mathrm{AsO}_{4}$, а в слабкокислому і нейтральному переважають негативно заряджені іони $-\mathrm{H}_{2} \mathrm{AsO}_{4}^{-}$. На етапі переходу в лужне середовище з'являються багатозарядні іони типу $\mathrm{HAsO}_{4}^{2-}$ та $\mathrm{AsO}_{4}^{3-}[5]$.

3 іншого боку, заряд поверхні глинистих мінералів також залежить від рН водного розчину. У кислому середовищі атоми кисню, що присутні на базальній поверхні глинистих мінералів у складі функціональних гідроксильних груп, у результаті взаємодії з молекулами води утворюють позитивно заряджені водневі комплекси ( $\mathrm{A}^{-}-$арсенат-іони):

$$
\begin{aligned}
& -\mathrm{SiO}+\mathrm{H}-\mathrm{OH} \stackrel{\mathrm{H}^{+}}{\longrightarrow}-\mathrm{Si}-\mathrm{OH}_{2}^{+}+\mathrm{OH}^{-}, \\
& -\mathrm{Si}-\mathrm{OH}_{2}^{+}+\mathrm{A}^{-} \leftrightarrow-\mathrm{Si}-\mathrm{OH}_{2} \cdots \mathrm{A}^{-} .
\end{aligned}
$$



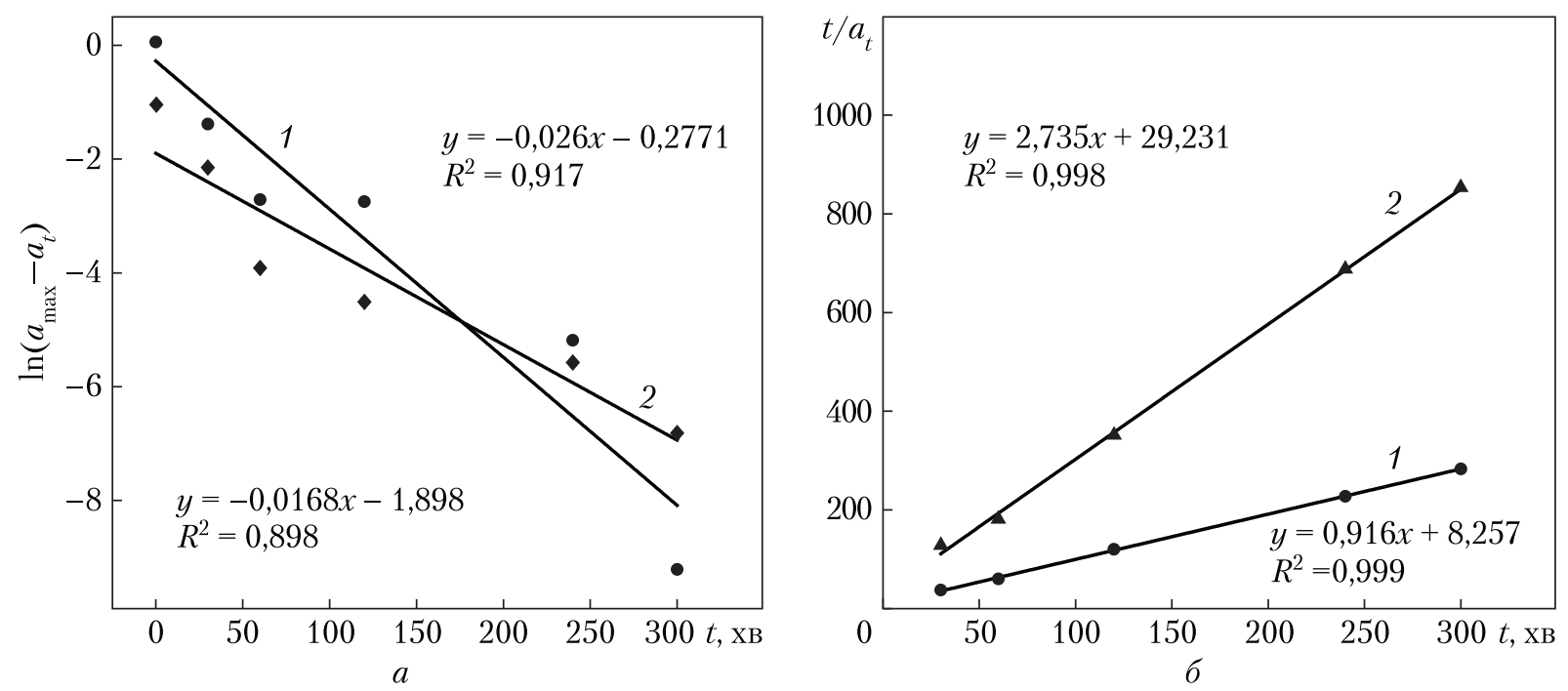

Puc. 2. Лінеаризація експериментальних даних сорбції $\mathrm{As}(\mathrm{V})$ на зразках $\mathrm{MMT}_{\mathrm{M}} \mathrm{Fe}^{0}$ (1) і ПГ-Fe $(2)$ в координатах кінетичних моделей псевдопершого $(a)$ та псевдодругого (б) порядків

Зі зростанням величини рН поверхня глинистих мінералів стає негативно зарядженою, що перешкоджає зближенню арсенат-аніонів із базальною поверхнею та призводить до зменшення величин сорбції:

$$
-\mathrm{SiOH}+\mathrm{OH}^{-} \leftrightarrow-\mathrm{SiO}^{-}+\mathrm{H}_{2} \mathrm{O} .
$$

Для зразків стабілізованого $\mathrm{Fe}^{0}$ величина $\mathrm{pH}$ водного середовища практично не впливає на процес вилучення As( V) у широкому діапазоні, що обумовлено електростатичною взаємодією між позитивно зарядженою поверхнею частинок нанорозмірного нульвалентного заліза та негативно зарядженою формою $\mathrm{H}_{2} \mathrm{AsO}_{4}^{-}$в діапазоні $\mathrm{pH} 3-7$ [13].

Дослідження впливу часу контакту між зразками стабілізованого нанорозмірного заліза та арсенат-іонами на процес сорбції показало, що їх видалення відбувається достатньо інтенсивно і час встановлення сорбційної рівноваги в системі становить 1 год за умов постійного струшування розчинів.

Для аналізу процесів кінетики сорбції арсенат-іонів одержаними сорбентами ПГ-Fе $\mathrm{i}$ MMT-Fe ${ }^{0}$ використовували дві кінетичні моделі адсорбції:

1) псевдопершого порядку (модель Лагергрена)

$$
\ln \left(a_{\max }-a_{t}\right)=\ln a_{\max }-k_{1} t
$$

де $a_{\max }-$ величина сорбції в рівновазі, мг $/ г ; a_{t}$ - величина сорбції в момент часу $t$ (хв), мг/г; $k_{1}$ - константа швидкості адсорбції моделі псевдопершого порядку, $\mathrm{xB}^{-1}$;

2) псевдодругого порядку

$$
\frac{t}{a_{t}}=\frac{1}{k_{2} a_{\max }^{2}}+\frac{t}{a_{\max }},
$$

де $k_{2}$ - константа швидкості адсорбції моделі псевдодругого порядку, г/(мг · хв). 
В основу моделі псевдопершого порядку покладено поняття адсорбційної ємності сорбенту. Дана модель пояснює зв'язок між швидкістю, з якою займаються адсорбційні центри, та кількістю вільних адсорбційних центрів, а модель псевдодругого порядку описує залежність адсорбційної здатності адсорбенту від часу. Вона враховує взаємодію між сорбатом і поверхнею сорбенту.

Значення констант $k_{1}$ та $k_{2}$ було отримано з графіків залежностей $\ln \left(a_{\max }-a_{t}\right)$ від $t$ та $t / a_{t}$ від $t$ відповідно (рис. 2). Розраховані параметри кінетичних моделей наведено в таблиці.

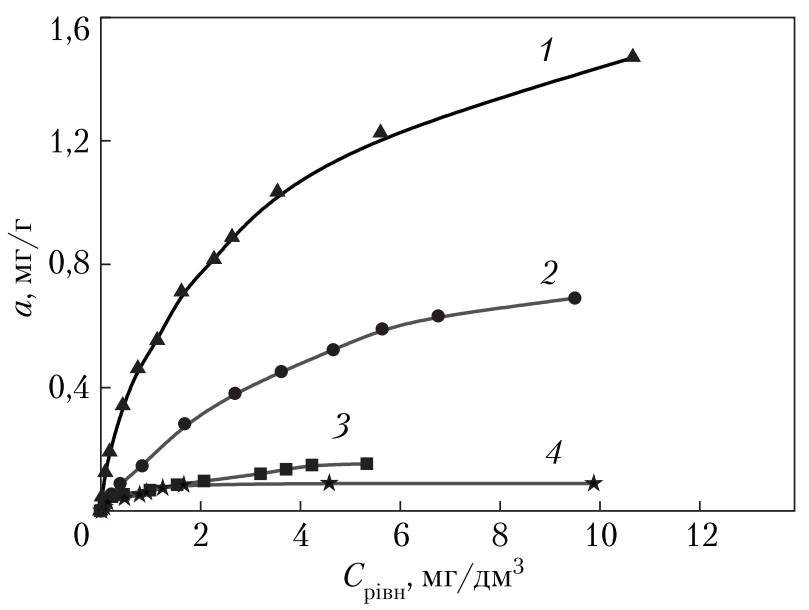

Puc. 3. Ізотерми сорбції $\mathrm{As}(\mathrm{V})$ на зразках: 1 MMT-Fe $^{0} ; 2-\Pi Г-\mathrm{Fe}^{0} ; 3-\mathrm{MMT} ; 4-\Pi \Gamma$

Отримані дані вказують на те, що кінетичні залежності сорбції As(V) зразками стабілізованого $\mathrm{Fe}^{0}$ краще описуються моделлю псевдодругого порядку $\left(R^{2}>0,99\right)$, яка враховує взаємодію між реакційними функціональними групами, які знаходяться на поверхні сорбційних матеріалів, та арсенат-іонами.

Відомо, що частинки нанорозмірного нульвалентного заліза мають “core-shell” структуру, що являє собою ядро $\mathrm{Fe}^{0}$, вкрите тонким поруватим шаром оксидів та гідроксидів $\mathrm{Fe}(\mathrm{II})$ і $\mathrm{Fe}(\mathrm{III})$ [14]. Процес сорбції арсенат-іонів починається саме на поверхні модифікованих мінералів:

$$
\begin{aligned}
& \equiv \mathrm{FeOH}+\mathrm{H}^{+} \leftrightarrow \equiv \mathrm{FeOH}_{2}^{+}, \\
& \equiv \mathrm{FeOH}_{2}^{+}+\mathrm{H}_{2} \mathrm{AsO}_{4}^{-} \leftrightarrow \equiv \mathrm{FeH}_{2} \mathrm{AsO}_{4}+\mathrm{H}_{2} \mathrm{O}, \\
& \equiv \mathrm{FeOH}_{2}^{+}+\mathrm{HAsO}_{4}^{2-} \leftrightarrow \equiv \mathrm{FeHAsO}_{4}^{-}+\mathrm{H}_{2} \mathrm{O} .
\end{aligned}
$$

Параметри кінетичних моделей сорбції $\mathrm{As}(\mathrm{V})$ зразками стабілізованого $\mathrm{Fe}^{0}(T=291 \mathrm{~K}, \mathrm{pH}=6,2)$

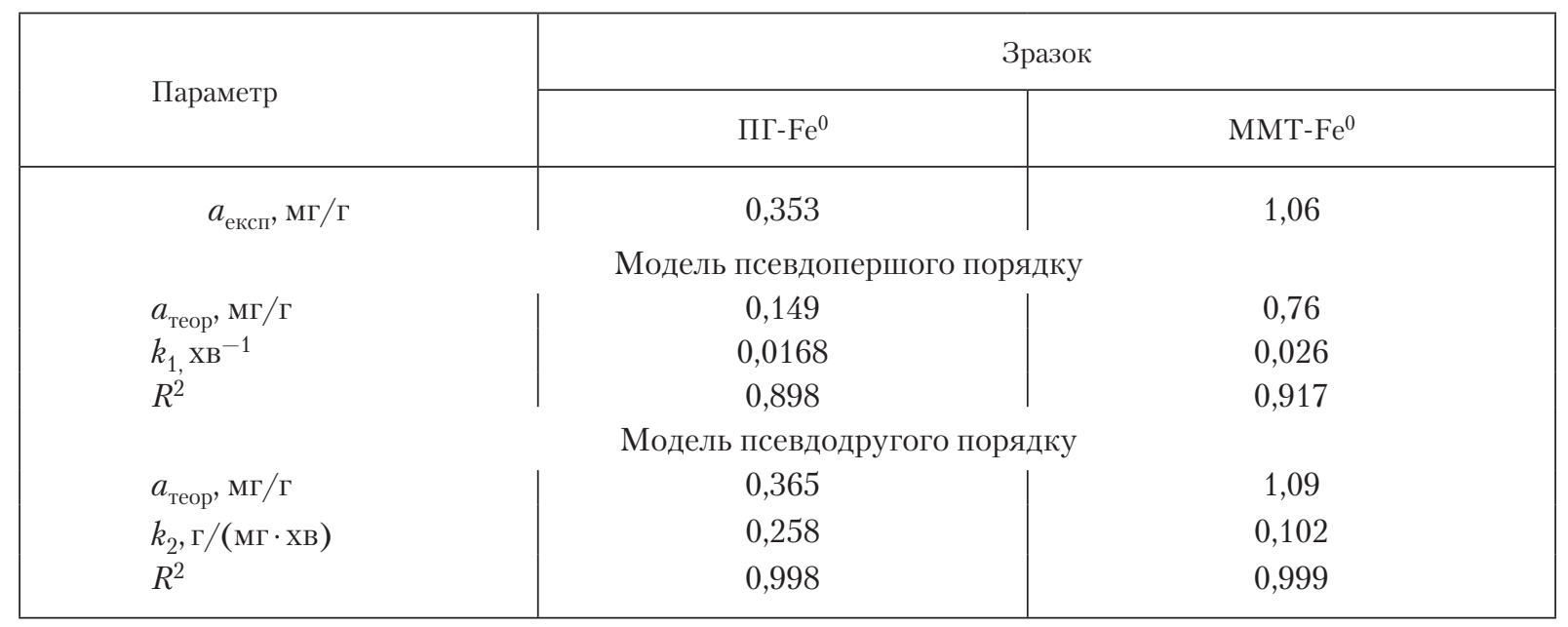


Після того, як усі зовнішні сорбційні центри заповнені адсорбатом, можливе проникнення арсенат-іонів у пори матеріалу, де відбувається внутрішня адсорбція. Зі зменшенням концентрації As(V) у розчині з часом швидкість дифузії також зменшується і досягається стан рівноваги [15]. Отже, кінетична модель псевдодругого порядку вказує на високу спорідненість між арсенат-іонами і сорбційними матеріалами.

На рис. 3 зображені ізотерми сорбції As(V) зразками стабілізованого нанорозмірного заліза при рН 6,2. Для порівняння показано також криві на вихідних мінералах. Отримані результати свідчать про те, що сорбційна здатність природних глинистих мінералів щодо арсенат-іонів незначна і досягає не більше 0,1 мг / г для ПГ і 0,15 мг/г для ММТ. При цьому на зразках стабілізованого $\mathrm{Fe}^{0}$ спостерігається зростання величин сорбції арсенат-іонів. Так, для MMT-Fe ${ }^{0}$ величина максимальної сорбції майже вдвічі перевищує таку для ПГ-Fе і становить 1,5 і 0,7 мг/г відповідно.

Таким чином, сорбенти на основі нанорозмірного заліза, нанесеного на поверхню природних глинистих мінералів монтморилоніту та палигорськіту, ефективно видаляють сполуки As( V) з водного середовища в широкому діапазоні величин рН. При цьому використання як стабілізаторів частинок $\mathrm{Fe}^{0}$ доступних та дешевих алюмосилікатів робить застосування таких композитів досить перспективним, особливо на стадії доочищення забруднених арсенвмісних вод.

\section{ЦИТОВАНА ЛІТЕРАТУРА}

1. Химия окружающей среды: Бокрис Дж. (ред). Москва: Химия, 1982. 671 с.

2. Kapaj S., Peterson H., Liber K., Bhattacharya P. Human health effects from chronic arsenic poisoning - a review. J. Environ. Sci. Health. Pt. A. 2006. 41, № 10. P. 2399-2428. https://doi.org/10.1080/10934520600873571

3. Adeloju S.B., Khan S., Patti A.F. Arsenic contamination of groundwater and its implications for drinking water quality and human health in under-developed countries and remote communities - a review. Appl. Sci. 2021. 11, № 4. P. 1926-1950. https://doi.org/10.3390/app11041926

4. Arsenic in ground water: geochemistry and occurrence: Welch A.H., Stollenwerk K.G. (Eds.). Dordrecht: Kluwer Academic Publishers, 2003. 488 p.

5. Осадчий В.І., Набиванець Б.Й., Линник П.М., Осадча Н.М., Набиванець Ю.Б. Процеси формування хімічного складу поверхневих вод. Київ: Ніка-Центр, 2013. 240 с.

6. Wang S., Mulligan C.N. Effect of natural organic matter on arsenic release from soils and sediments into groundwater. Environ. Geochem. Health. 2006. 28. P. 197-214. https://doi.org/10.1007/s10653-005-9032-y

7. Линник П.Н. Мышьяк в природных водах: формы нахождения, особенности миграции, токсичность (обзор). Гидробиол. журн. 2015. 51, № 4. С. 91-116. URL: http://dspace.nbuv.gov.ua/handle/123456789/126284 (Дата звернення: 28.04.2021).

8. Mohanty D. Conventional as well as emerging arsenic removal technologies - a critical review. Water Air Soil Pollut. 2017. 228. P. 381-402. https://doi.org/10.1007/s11270-017-3549-4

9. Babu D.S., Nidheesh P.V. A review on electrochemical treatment of arsenic from aqueous medium. Chem. Eng. Commun. 2021. 208, № 3. P. 389-410. https://doi.org/10.1080/00986445.2020.1715956

10. Weerasundara L., Ok Y.-S., Bundschuh J. Selective removal of arsenic in water: A critical review. Environ. Pollut. 2021. 268, Pt. B., 115668. https://doi.org/10.1016/j.envpol.2020.115668

11. Trujillo-Reyes J., Peralta-Videa J.R., Gardea-Torresdey J.L. Supported and unsupported nanomaterials for water and soil remediation: Are they a useful solution for worldwide pollution? J. Hazard. Mater. 2014. 280. P. 487-503. https://doi.org/10.1016/j.jhazmat.2014.08.029

12. Тобілко В.Ю., Корнілович Б.Ю. Синтез та сорбційні властивості композиційних матеріалів на основі нанорозмірного $\mathrm{Fe}^{0}$. Східно-Свропейський журнал передових технологій. 2015. 4, № 5. С. 22-27. https://doi.org/10.15587/1729-4061.2015.46580 
13. Wu C., Tu J., Liu W., Zhang J., Chu S., Lu G., Lin Z., Dang Z. The double influence mechanism of pH on arsenic removal by nano zero valent iron: electrostatic interactions and the corrosion of Fe ${ }^{0}$. Environ. Sci. Nano. 2017. 4. P. 1544-1552. https://doi.org/10.1039/C7EN00240H

14. Yan W., Herzing A.A., Kiely C.J., Zhang W.-X. Nanoscale zero-valent iron (nZVI): aspects of the core-shell structure and reactions with inorganic species in water. J. Contam. Hydrol. 2010. 118. P. 96-104. https://doi.org/10.1016/j.jconhyd.2010.09.003

15. Bhowmick S., Chakraborty S., Mondal P., Van Renterghem W., Van den Berghe S., Roman-Ross G., Chatterjee D., Iglesias M. Montmorillonite-supported nanoscale zero-valent iron for removal of arsenic from aqueous solution: Kinetics and mechanism. Chem. Eng.J. 2014. 243. P. 14-23.

https://doi.org/10.1016/j.cej.2013.12.049

Надійшло до редакції 01.07.2021

\section{REFERENCES}

1. Bockris, J. O`M. (Ed.). (1982). Environmental Chemistry. Moscow: Khimia (in Russian).

2. Kapaj, S., Peterson, H., Liber, K. \& Bhattacharya, P. (2006). Human health effects from chronic arsenic poisoning - a review. J. Environ. Sci. Health. Pt. A., 41, No. 10, pp. 2399-2428. https://doi.org/10.1080/10934520600873571

3. Adeloju, S. B., Khan, S. \& Patti, A. F. (2021). Arsenic contamination of groundwater and its implications for drinking water quality and human health in under-developed countries and remote communities - a review. Appl. Sci., 11, No. 4, pp. 1926-1950. https://doi.org/10.3390/app11041926

4. Welch, A. H \& Stollenwerk, K. G. (Eds.). (2003). Arsenic in ground water: geochemistry and occurrence: Dordrecht: Kluwer Academic Publishers.

5. Osadchyi, V. I., Nabyvanets, B. Y., Lynnyk, P. M \& Osadcha, N. M. (2013). Processes formation of surface water chemical composition. Kyiv: Nika-Centre (in Ukrainian).

6. Wang, S. \& Mulligan, C. N. (2006). Effect of natural organic matter on arsenic release from soils and sediments into groundwater. Environ. Geochem. Health, 28, pp. 197-214. https://doi.org/10.1007/s10653-005-9032-y

7. Lynnyk, P. M. (2015). Arsenic in water: forms of occurrence, migration features, toxicity (review). Hydrobiol. J., 51, No. 4, pp. 91-116 (in Russian). Retrieved from http://dspace.nbuv.gov.ua/handle/123456789/126284

8. Mohanty, D. (2017). Conventional as well as emerging arsenic removal technologies - a critical review. Water Air Soil Pollut., 228, pp. 381-402. https://doi.org/10.1007/s11270-017-3549-4

9. Babu, D. S. \& Nidheesh, P. V. (2021). A review on electrochemical treatment of arsenic from aqueous medium. Chem. Eng. Commun., 208, No. 3. pp. 389-410. https://doi.org/10.1080/00986445.2020.1715956

10. Weerasundara, L., Ok, Y.-S. \& Bundschuh, J. (2021). Selective removal of arsenic in water: A critical review. Environ. Pollut., 268, Pt. B., 115668. https://doi.org/10.1016/j.envpol.2020.115668

11. Trujillo-Reyes, J., Peralta-Videa, J. R. \& Gardea-Torresdey, J. L. (2014). Supported and unsupported nanomaterials for water and soil remediation: Are they a useful solution for worldwide pollution? J. Hazard. Mater., 280, pp. 487-503. https://doi.org/10.1016/j.jhazmat.2014.08.029

12. Tobilko, V. Yu. \& Kornilovych, B. Yu. (2015). Synthesis and sorption properties of composite materials based on nanoscale $\mathrm{Fe}^{0}$. Eastern-European Journal of Enterprise Technologies, 4, No. 5, pp. 22-27 (in Ukrainian). https://doi.org/10.15587/1729-4061.2015.46580

13. Wu, C., Tu, J., Liu, W., Zhang, J., Chu, S., Lu, G., Lin, Z. \& Dang, Z. (2017). The double influence mechanism of $\mathrm{pH}$ on arsenic removal by nano zero valent iron: electrostatic interactions and the corrosion of $\mathrm{Fe}^{0}$. Environ. Sci. Nano., 4, pp. 1544-1552. https://doi.org/10.1039/C7EN00240H

14. Yan, W., Herzing, A. A., Kiely, C. J. \& Zhang, W.-X. (2010). Nanoscale zero-valent iron (nZVI): aspects of the core-shell structure and reactions with inorganic species in water. J. Contam. Hydrol., 118. pp. 96-104. https://doi.org/10.1016/j.jconhyd.2010.09.003

15. Bhowmick, S., Chakraborty, S., Mondal, P., Van Renterghem, W., Van den Berghe, S., Roman-Ross, G., Chatterjee, D. \& Iglesias, M. (2014). Montmorillonite-supported nanoscale zero-valent iron for removal of arsenic from aqueous solution: Kinetics and mechanism. Chem. Eng. J., 243, pp. 14-23.

https://doi.org/10.1016/j.cej.2013.12.049

Received 01.07.2021 
A.I. Bondarieva, https://orcid.org/0000-0003-3064-1725

Yu.M. Kholodko, https://orcid.org/0000-0002-2514-767X

V.Yu. Tobilko, https://orcid.org/0000-0002-1800-948X

B.Yu. Kornilozych, https://orcid.org/0000-0002-6393-6880

National Technical University of Ukraine "Igor Sikorsky Kyiv Polytechnic Institute"

E-mail: a.i.bondarieva@gmail.com

\section{REMOVAL OF ARSENIC COMPOUNDS FROM WATER AND WASTEWATER USING NANO-SIZED IRON}

We have investigated the physicochemical properties of the removal of arsenic compounds from water and wastewater utilizing nanoscale iron deposited on the surface of clay minerals. It is found that the obtained materials have much better sorption properties in terms of arsenic removal from aqueous solutions compared to natural silicates. Kinetic data of sorption of arsenate ions by samples of stabilized nanoscale iron were analyzed using the pseudo-first-order and pseudo-second-order models. Kinetic studies show that the adsorption As(V) process is better described by the pseudo-second order model. The obtained results show that sorbents based on nanoscale iron effectively remove toxic arsenic ions from contaminated water.

Keywords: arsenic, water treatment, adsorption, nanoscale iron, silicate sorbents. 